\title{
Variability in upwelling across the tropical tropopause and correlations with tracers in the lower stratosphere
}

\author{
M. Abalos ${ }^{1}$, W. J. Randel ${ }^{2}$, and E. Serrano ${ }^{1}$ \\ ${ }^{1}$ Depto. de Geofísica y Meteorología, Universidad Complutense de Madrid, Madrid, Spain \\ ${ }^{2}$ National Center for Atmospheric Research, Boulder, Colorado, USA \\ Correspondence to: M. Abalos (mabalosa@fis.ucm.es)
}

Received: 12 July 2012 - Published in Atmos. Chem. Phys. Discuss.: 31 July 2012

Revised: 12 October 2012 - Accepted: 19 November 2012 - Published: 4 December 2012

\begin{abstract}
Temporal variability of the upwelling near the tropical tropopause on daily to annual timescales is investigated using three different estimates computed from the ERA-Interim reanalysis. These include upwelling archived by the reanalysis, plus estimates derived from thermodynamic and momentum balance calculations. Substantial variability in upwelling is observed on both seasonal and subseasonal timescales, and the three estimates show reasonably good agreement. Tropical upwelling should exert strong influence on temperatures and on tracers with large vertical gradients in the lower stratosphere. We test this behavior by comparing the calculated upwelling estimates with observed temperatures in the tropical lower stratosphere, and with measurements of ozone and carbon monoxide (CO) from the Aura Microwave Limb Sounder (MLS) satellite instrument. Time series of temperature, ozone and $\mathrm{CO}$ are well correlated in the tropical lower stratosphere, and we quantify the influence of tropical upwelling on this joint variability. Strong coherent annual cycles observed in each quantity are found to reflect the seasonal cycle in upwelling. Statistically significant correlations between upwelling, temperatures and tracers are also found for sub-seasonal timescales, demonstrating the importance of upwelling in forcing transient variability in the lower tropical stratosphere.
\end{abstract}

\section{Introduction}

The mean circulation in the tropical lower stratosphere is characterized by upwelling, which transports air masses across the tropical tropopause into the lower stratosphere. This constitutes the ascending branch of the global mean stratospheric circulation, which is completed by poleward flow in each hemisphere and subsidence at high latitudes (i.e. the so-called Brewer-Dobson circulation, Brewer, 1949; Dobson, 1956). This wave-driven circulation strongly influences the chemical composition and thermodynamic balance of the global stratosphere (e.g. Andrews et al., 1987). Despite the key role of tropical upwelling in the stratospheric circulation, there are significant uncertainties regarding its intensity and variability and the associated forcing mechanisms. Due to its small magnitude $\left(\sim 10^{-4} \mathrm{~m} \mathrm{~s}^{-1}\right)$ and the lack of direct measurements, lower stratospheric tropical upwelling is poorly constrained in current meteorological analysis systems; for example, Iwasaki et al. (2009) show substantial discrepancies in upwelling among different reanalysis data sets. Alternatively, the tropical upwelling has been estimated indirectly using thermodynamic balance (Gille et al., 1987; Rosenlof, 1995), momentum balance (Randel et al., 2002), and via variations in tracer concentration such as water vapor (e.g. Mote et al., 1996; Niwano et al., 2006; Schoeberl et al., 2008b). Observations show that fluctuations in tropical upwelling have an impact on the thermal and chemical behavior of the tropical tropopause layer (TTL), a transition region characterized by strong dynamical and chemical vertical gradients (Fueglistaler et al., 2009a). For instance, the strong annual cycle in temperature observed above the tropical tropopause is linked to the seasonality of the BrewerDobson circulation (Reed and Vlcek, 1969; Yulaeva et al., 1994). Randel et al. (2002) show that the vertical structure of the amplitude of the temperature annual cycle (peaking near $70 \mathrm{hPa}$ ) is consistent with the long radiative timescales in this region. They also highlight that sub-seasonal variations in temperature and tropical upwelling are closely coupled. 
High vertical resolution observations in the lower stratosphere also reveal a large annual cycle in ozone confined to a narrow region above the tropical tropopause (Logan, 1999; Folkins et al., 2006; Randel et al., 2007). Folkins et al. (2006) reproduce quite successfully the observed annual cycle by using a simple model including seasonal variations in tropical upwelling and in high altitude convective outflow. Using ozonesonde and satellite observations Randel et al. (2007) show that the temporal phasing and vertical structure of the ozone seasonal cycle can be explained by the seasonality in tropical upwelling acting on the strong background ozone vertical gradient. They also note that the seasonal cycle in ozone is approximately in phase with the temperature cycle, and both amplitudes show a very similar vertical structure. Schoeberl et al. (2008a) observe that there is almost no phase shift of the annual cycle in ozone with height in the lower tropical stratosphere, and this is consistent with seasonal variations in upwelling driving annual variations in ozone. In addition, Folkins et al. (2006), Randel et al. (2007) and Schoeberl et al. (2008a) analyze the annual cycle in carbon monoxide $(\mathrm{CO})$ observed in this region, and conclude that the upwelling also has a dominant role in forcing this cycle (because of the strong background vertical gradient above the tropopause). Furthermore, it has been suggested that a comprehensive understanding of thermal behavior in this region must include a feedback of the ozone radiative effects on temperature (Chae and Sherwood, 2007; Fueglistaler et al., 2011). While there is general agreement on the origin of the annual cycle in temperature above the tropical tropopause, there is still controversy on the primary forcing mechanism(s) of the observed annual cycle in tracer concentrations (ozone and CO). For instance, Konopka et al. (2010) and Ploeger et al. (2012) suggest that in-mixing of air from the extra-tropics into the TTL makes a major contribution to the seasonal cycle in ozone concentration above the tropical tropopause. In particular, they propose that horizontal transport associated with the upper-level circulation of the Asian monsoon plays a dominant role in building the ozone maximum observed in boreal summer. This result, based on trajectory calculations using the Chemistry Lagrangian Transport Model of the Stratosphere (CLaMS), is in contrast with the view that the seasonal cycle in ozone is mainly forced by tropical upwelling (e.g. Randel et al., 2007). In addition to the seasonal cycle, high-temporal resolution satellite measurements of ozone and $\mathrm{CO}$ reveal variability on subseasonal timescales in this region. The analysis of these faster variations can provide complementary information on the relative roles of the different forcing mechanisms.

The aim of the present study is to investigate the relationships between tropical upwelling variability and the fluctuations in temperature and the concentrations of ozone and $\mathrm{CO}$ just above the tropical tropopause across a broad range of timescales. We seek to understand and quantify uncertainties in tropical upwelling by calculating three different estimates from reanalysis data. We then combine the meteoro- logical data with satellite observations of tracer concentrations and examine correlated variability among temperature, ozone and $\mathrm{CO}$ in terms of coherence with upwelling, focusing separately on seasonal and sub-seasonal timescales.

\section{Data and upwelling calculations}

\subsection{Satellite and meteorological data}

Observations from the Microwave Limb Sounder (MLS) onboard the Aura satellite (Waters et al., 2006) cover now more than eight years (starting September 2004). We use zonal mean daily averaged measurements of ozone and $\mathrm{CO}$ for the period September 2004 to December 2010 on a $7.5^{\circ}$ latitude grid, and analyze the time series averaged over the latitude band $18.75^{\circ} \mathrm{N}-\mathrm{S}$. This band is representative of the width of the tropics in the lowermost stratosphere, based on the autocorrelations of temperature, upwelling and tracers near the equator with other latitudes. There are three pressure levels within the tropical tropopause layer at which MLS measures carbon monoxide (147, 100 and $68 \mathrm{hPa}$ ) and five for ozone $(147,121,100,83$ and $68 \mathrm{hPa})$. The vertical resolution of MLS ozone is approximately $3 \mathrm{~km}$ (Froidevaux et al., 2006), while the resolution for CO is $4.5 \mathrm{~km}$ (Livesey et al., 2008). The present study focuses on the effect of tropical upwelling at and above the tropical tropopause, so only the levels of $100 \mathrm{hPa}$ and above are considered. As a note, water vapor is not included in this analysis because it is largely affected by dehydration near the cold point tropopause, and is less influenced by transport.

Upwelling estimates are derived from temperature and wind fields from the ERA-Interim reanalysis (Dee et al., 2011) generated at the European Centre for Medium-Range Weather Forecasts (ECMWF), with calculations described below. In view of the results of Seviour et al. (2011), who show large diurnal variability in ERA-Interim upwelling results, we compute daily averages from 6-hourly data. The meteorological data is archived on 60 vertical levels, with a horizontal resolution of $1.5^{\circ} \times 1.5^{\circ}$. The ERA-Interim reanalysis has been shown to provide an improved representation of the stratospheric Brewer-Dobson circulation and age of air compared to the previous ECMWF reanalysis, ERA-40 (Monge-Sanz et al., 2007; Fueglistaler et al., 2009b). Iwasaki et al. (2009) and Seviour et al. (2011) show that ERA-Interim yields less noisy vertical velocities compared to other reanalyses. We choose pressure levels for this analysis of 100, 80 and $70 \mathrm{hPa}$, to nearly match the levels of constituent observations (broad layers centered at 100, 83 and $68 \mathrm{hPa}$ ).

Time series of tropical zonal mean temperatures in the lower stratosphere from the ERA-Interim data are shown in Fig. 1 (averaged over $18^{\circ} \mathrm{N}-\mathrm{S}$ ), together with ozone and $\mathrm{CO}$ concentrations from MLS as described above. Each of the time series in Fig. 1 is standardized to unit variance, and $\mathrm{CO}$ is plotted on an inverted scale. The results in Fig. 1 show 


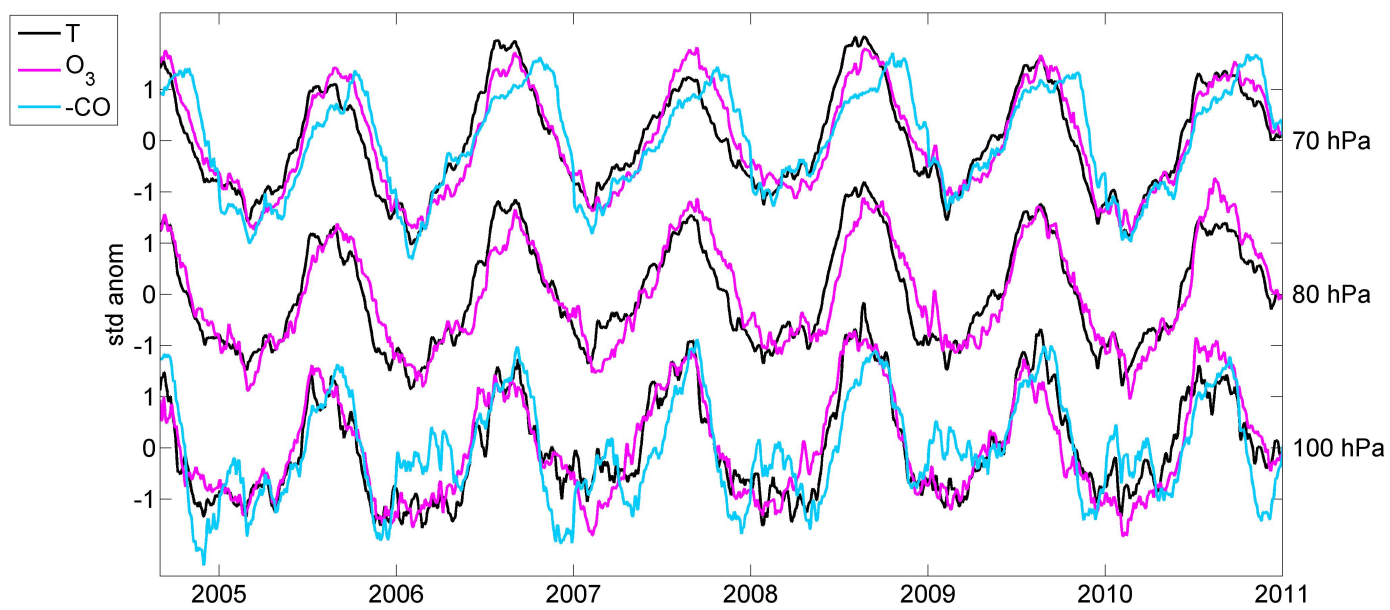

Fig. 1. Time series of standardized anomalies of daily temperatures from ERA-Interim and ozone and CO mixing ratio measurements from MLS averaged over $18^{\circ} \mathrm{N}-\mathrm{S}$ at three pressure levels across the tropical tropopause $(70,80$ and $100 \mathrm{hPa}$ from top to bottom; levels shown for MLS are 68, 83 and $100 \mathrm{hPa}$ ). 3-days running means are applied to the daily series. CO concentrations are plotted on a reversed scale in order to highlight the common fluctuations.

coherence among the time series of reanalysis temperatures and the completely independent satellite constituent observations. The common variability is especially evident in the large annual cycles, which are approximately in phase over the three pressure levels (with the -inverted- minimum in $\mathrm{CO}$ having a time lag of $\sim 2$ months compared to the maxima in temperature and ozone at $70 \mathrm{hPa}$ ). There is an additional semi-annual component evident for $\mathrm{CO}$ at $100 \mathrm{hPa}$, related to seasonally dependent tropospheric sources and convective transport, as discussed further in Sect. 3. There is also evidence for correlated sub-seasonal variability in Fig. 1, suggesting that these variations share a common forcing. In this study we examine the role of the tropical upwelling variability in forcing these joint fluctuations of temperature, ozone and $\mathrm{CO}$.

\subsection{Upwelling calculations}

Three different estimates of zonal average tropical upwelling are obtained using the temperature and wind fields from ERA-Interim, including direct upwelling from the reanalysis, and estimates calculated from thermodynamic and momentum balances. The details of these latter calculations can be found in Randel et al. (2002); here we focus on highlighting the main uncertainties associated with each estimate. The first, which will be referred to as $\bar{w}^{*}$, is the vertical component of the residual circulation in the Transformed Eulerian Mean (TEM) formulation in log-pressure coordinates as defined in Andrews et al. (1987):

$\bar{w}^{*} \equiv \bar{w}+\frac{1}{a \cos \phi} \frac{\partial}{\partial \phi}\left(\cos \phi \frac{\overline{v^{\prime} T^{\prime}}}{S}\right)$

where $S$ is the static stability parameter, $S=H N^{2} / R$, a function of the Brunt-Väisälä frequency $(N)$, with $H=7 \mathrm{~km}$ and $R=287 \mathrm{~m}^{2} \mathrm{~s}^{-2} \mathrm{~K}^{-1}$, and the rest of the notation is the same as in Andrews et al. (1987). In the tropics the $\overline{v^{\prime} T^{\prime}}$ term in Eq. (1) is small, so that $\bar{w}^{*}$ primarily depends on the reanalysis zonal mean vertical velocity $(\bar{w})$. Although one of the major improvements in this third-generation reanalysis compared to its predecessor ERA- 40 is the weaker and hence more realistic stratospheric circulation (Dee et al., 2011), there are still large uncertainties in this magnitude, especially near the tropical tropopause.

The second estimate is calculated from the momentum balance using the expression (11) in Randel et al. (2002), obtained combining the TEM momentum and continuity equations:

$\left\langle\bar{w}_{m}^{*}\right\rangle(z)=$

$\frac{-e^{z / H}}{\int_{-\phi_{0}}^{\phi_{0}} a \cos \phi d \phi}\left\{\int_{z}^{\infty} \frac{e^{-z^{\prime} / H} \cos \phi}{\hat{f}\left(\phi, z^{\prime}\right)}\left[D F\left(\phi, z^{\prime}\right)-\bar{u}_{t}\left(\phi, z^{\prime}\right)\right]_{\bar{m}} d z^{\prime}\right\}_{-\phi_{0}}^{\phi_{0}}$

Here $D F$ is the scaled Eliassen-Palm flux divergence, $\hat{f}=$ $f-(1 / a \cos \phi)(\partial / \partial \phi)(\bar{u} \cos \phi)$, where $f$ is the Coriolis parameter, and $\bar{u}_{t}$ is the zonal mean zonal wind tendency. This expression gives the tropical upwelling at a fixed pressure level and averaged over a latitudinal band $\left( \pm \phi_{0}\right)$ which is in balance with the circulation and eddy forcing calculated from the reanalysis. To simplify the calculations, the integrand is computed on constant latitudes instead of along isolines of constant zonal mean angular momentum, since at the latitudinal boundaries we use $\left( \pm 18^{\circ}\right)$ these isolines are approximately vertical. The divergence of the Eliassen-Palm flux includes eddy fluxes calculated from the three-dimensional temperature and wind fields from the reanalysis, such that a key uncertainty in the calculation of $\bar{w}_{m}^{*}$ is associated with the unresolved waves that are not taken into account in these 
fluxes. As a note, the model simulations in Garcia and Randel (2008) and Calvo and Garcia (2009) suggest that, for the range of latitude/altitude considered here, resolved waves explain most of the upwelling.

The third estimate of upwelling is derived by iteratively solving the TEM thermodynamic equation (Eq. (4) below) neglecting the eddy transport term (last term on the right hand side in Eq. (4)) and the TEM continuity equation:

$\frac{1}{a \cos \phi} \frac{\partial}{\partial \phi}\left(\bar{v}^{*} \cos \phi\right)+e^{z / H} \frac{\partial}{\partial z}\left(\bar{w}^{*} e^{-z / H}\right)=0$

following the procedures described in Rosenlof (1995). In this calculation one relevant source of uncertainty is associated with the heating rates $(Q)$ in the thermodynamic equation. For levels at and above $100 \mathrm{hPa}$, radiative heating is the primary diabatic forcing, and hence $\bar{w}_{Q}^{*}$ can be estimated using an accurate radiative heating code. We use the heating rates from the National Center for Atmospheric Research Column Radiation Model (NCAR-CRM; Gettelman et al., 2004) with input of daily ERA-Interim temperatures and MLS ozone. The annual mean heating rates provided by this model agree reasonably well with other estimates near the tropical tropopause in terms of the magnitude and the vertical structure (Gettelman et al., 2004). Also the seasonality in our calculations is consistent with that shown in Yang et al. (2008), with highest values in DJF and lowest in JJA. Our results are $\sim 0.1 \mathrm{~K} \mathrm{day}^{-1}$ higher in the annual mean compared to Yang et al. (2008), but this difference is within the range of uncertainty defined by the spread of a set of five different estimates shown in Gettelman et al. (2004). A more relevant difference is that our calculations do not result in near-zero heating rates during $\mathrm{NH}$ summer across $\sim 70$ to $50 \mathrm{hPa}$, as shown in Yang et al. (2008). As a consequence, the amplitude of the seasonal cycle in our heating rates over these levels $\left(\sim 0.1 \mathrm{~K} \mathrm{day}^{-1}\right)$ is approximately half of theirs. Nevertheless, the interpretation of the near-zero heating rates in Yang et al. (2008) is not clear to us, as they imply nearzero downward net mass flux outside the tropics in order to satisfy mass continuity. Finally, we note that our calculations do not include the effects of clouds on the radiative balance. However, according to Yang et al. (2010), the net effect of clouds on the zonal mean heating rates in the tropics is relatively small $\left(\leq-0.05 \mathrm{~K} \mathrm{day}^{-1}\right)$ at and above the tropical tropopause.

One aspect of the $\bar{w}_{Q}^{*}$ calculations is that the computed vertical velocities may not satisfy the constraint of zero net mass flux across a pressure surface (Rosenlof, 1995). Hence, the calculated vertical velocities require some adjustment to enforce this constraint, although the method of making this adjustment is arbitrary. Figure 2 shows a comparison of the latitudinal profile of the three estimates of upwelling, for the annual mean of the entire period. Two different calculations of $\bar{w}_{Q}^{*}$ are also included, based on making a constant adjustment independent of latitude or only adjusting values over $45^{\circ} \mathrm{N}-\mathrm{S}$. The different adjustments yield very similar values

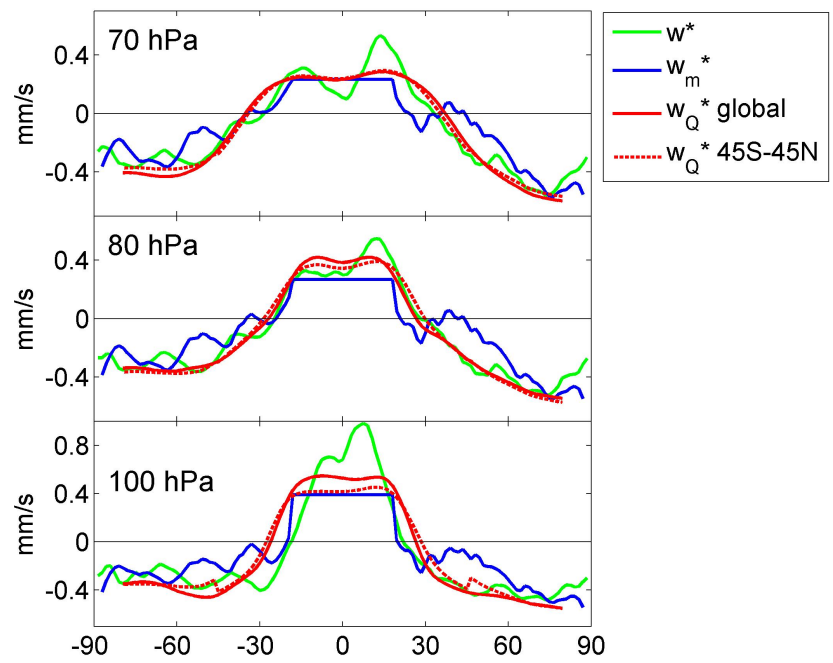

Fig. 2. Latitudinal structure of the three upwelling estimates at the indicated pressure levels (70, 80 and $100 \mathrm{hPa}$ from top to bottom). Green: residual circulation $\left(\bar{w}^{*}\right)$ blue: momentum balance estimate $\left(\bar{w}_{m}^{*}\right)$, and red: thermodynamic estimate $\left(\bar{w}_{Q}^{*}\right)$. Two red lines are shown: the solid line is the thermodynamic upwelling estimate computed with the global adjustment and the dashed line adjusting only within the range $45^{\circ} \mathrm{N}-\mathrm{S}$ (see text for details) $\left(\mathrm{mm} \mathrm{s}^{-1}\right)$.

of $\bar{w}_{Q}^{*}$ at $70 \mathrm{hPa}$, but larger variations are found at lower levels, where the adjustment focused over low latitudes provides smaller values of upwelling. This could be related to the larger contribution of the eddy term in the thermodynamic balance (Eq. 4) at these lower levels, which is confined to low latitudes (results based on analysis of ERA-Interim data, not shown here). The eddy term is neglected in our calculations of $\bar{w}_{Q}^{*}$, and this is a source of bias for this estimate (particularly at $80 \mathrm{hPa}$, where this term is largest), as further discussed in Sect. 3.1. By adjusting $\bar{w}_{Q}^{*}$ only in the range $45^{\circ} \mathrm{N}$ $\mathrm{S}$ we partly account for these larger biases at low latitudes, and this is the $\bar{w}_{Q}^{*}$ used throughout the rest of this work. On the other hand, the vertical velocity can be obtained from momentum balance everywhere except in the deep tropics, where $\hat{f} \rightarrow 0$, and hence Eq. (2) yields a constant value for $\bar{w}_{m}^{*}$ throughout the width of the tropics $\left(18^{\circ} \mathrm{N}-\mathrm{S}\right)$, as shown in Fig. 2.

\subsection{Comparisons of upwelling estimates}

The time average comparisons in Fig. 2 show overall agreement in the magnitude and latitudinal structure of all the estimates, with the upwelling from reanalysis, $\bar{w}^{*}$, showing somewhat stronger tropical upwelling compared to $\bar{w}_{m}^{*}$ and $\bar{w}_{Q}^{*}$, especially at $100 \mathrm{hPa}$. Note that the magnitude of $\bar{w}_{Q}^{*}$ is likely overestimated at $80 \mathrm{hPa}$ in the tropics, as discussed in Sect. 3.1. Time series of each of the upwelling estimates averaged over $18^{\circ} \mathrm{N}-\mathrm{S}$ are shown in Fig. 3 for pressure levels 100,80 and $70 \mathrm{hPa}$. This figure also shows corresponding mean seasonal cycles, calculated as monthly averages over 


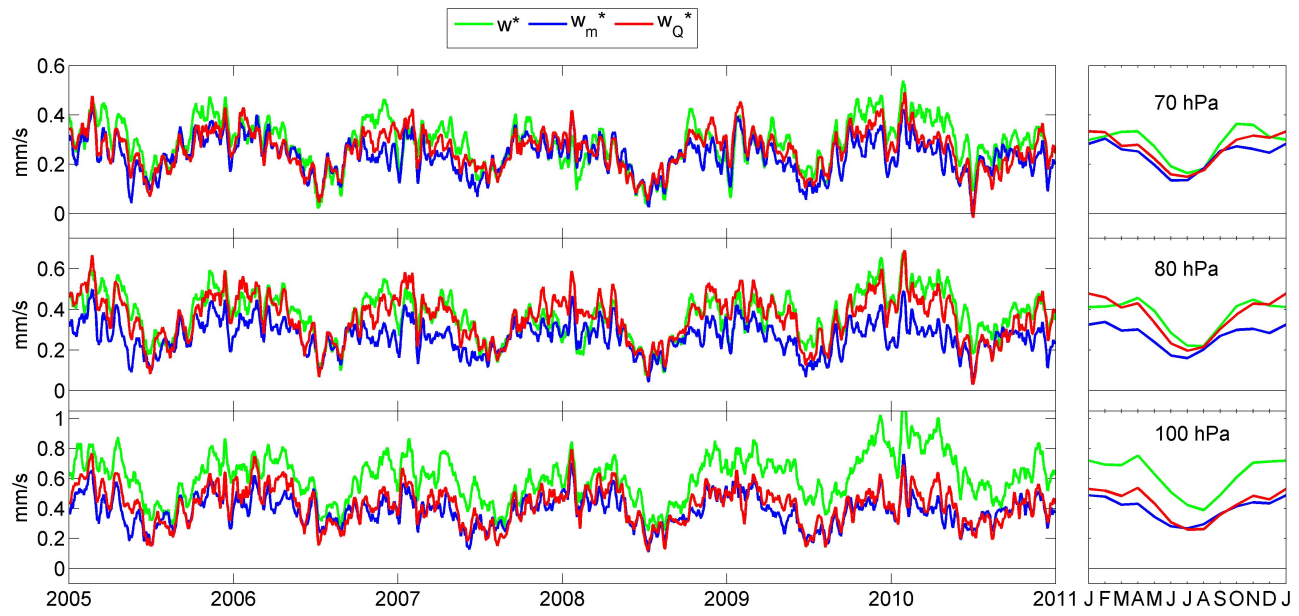

Fig. 3. Time series and mean seasonal cycles of the three upwelling estimates averaged over $18^{\circ} \mathrm{N}-\mathrm{S}$ at 70,80 and $100 \mathrm{hPa}$ (top to bottom panels). Green: residual circulation $\left(\bar{w}^{*}\right)$, blue: momentum balance estimate $\left(\bar{w}_{m}^{*}\right)$, and red: thermodynamic estimate $\left(\bar{w}_{Q}^{*}\right)$. 11-days running means are applied to the time series. The annual cycles are calculated as monthly means over 2005-2010 (mm s$\left.{ }^{-1}\right)$.

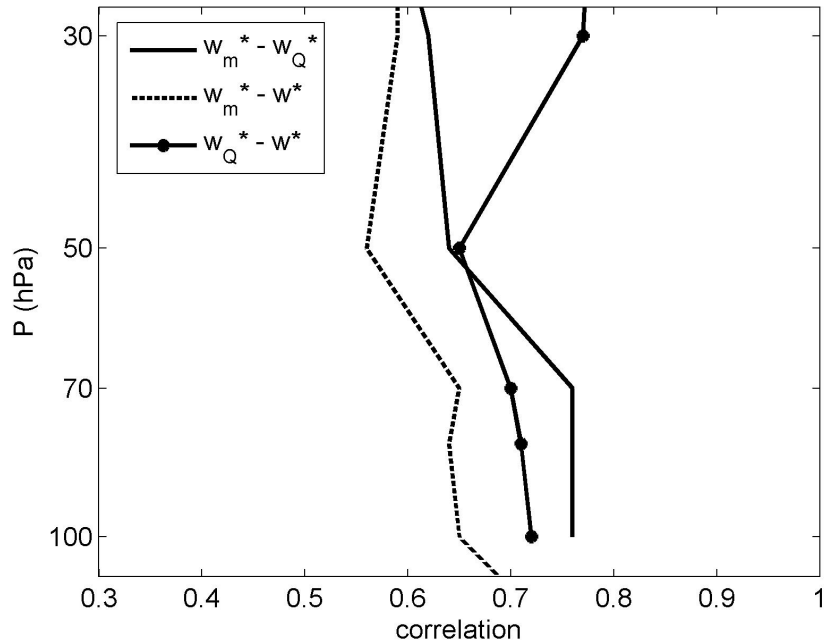

Fig. 4. Linear correlations among the time series of the three upwelling estimates as a function of pressure.

the entire data record. Figure 3 shows overall good agreement among the time series and the mean seasonal variation of the three upwelling estimates, especially between $\bar{w}_{m}^{*}$ and $\bar{w}_{Q}^{*}$. Inspection of the variability in the time series reveals strong similarities among the three estimates, showing numerous common fluctuations on a wide range of timescales. Note that the good agreement between $\bar{w}_{m}^{*}$ and $\bar{w}_{Q}^{*}$ suggests that $\bar{w}_{m}^{*}$ may be accurately calculated from resolved eddy fluxes alone. Correlations between the different estimates are shown in Fig. 4. The correlations among $\bar{w}^{*}, \bar{w}_{m}^{*}$ and $\bar{w}_{Q}^{*}$, in the tropical lower stratosphere are around 0.64-0.76. These fairly high correlations between the estimates are encouraging, given the uncertainties described above and the very different approaches followed to compute them. The degree of agreement among these estimates reflects a reasonably good understanding of the seasonal and sub-seasonal variability in tropical upwelling.

\section{Co-variations of upwelling, temperatures and tracers}

A simple explanation for the strong correlations between temperatures and tracers in the tropical lower stratosphere (Fig. 1) is that they result primarily from forcing by tropical upwelling. The origin of this coupling can be appreciated by examining the zonal mean thermodynamic and tracer mixing ratio continuity equations in the TEM formalism (Andrews et al., 1987):

$$
\begin{aligned}
& \frac{\partial \bar{T}}{\partial t}=-\bar{v}^{*} \frac{1}{a} \frac{\partial \bar{T}}{\partial \phi}-\bar{w}^{*} S+\bar{Q} \\
& -\frac{1}{e^{-z / H}} \frac{\partial}{\partial z}\left[e^{-z / H}\left(\overline{v^{\prime} T^{\prime}} \frac{\partial \bar{T} / \partial \phi}{a \cdot S}+\overline{w^{\prime} T^{\prime}}\right)\right] \\
& \frac{\partial \bar{\chi}}{\partial t}=-\bar{v}^{*} \frac{1}{a} \frac{\partial \bar{\chi}}{\partial \phi}-\bar{w}^{*} \frac{\partial \bar{\chi}}{\partial z}+\nabla \cdot \boldsymbol{M}+P-L
\end{aligned}
$$

In the continuity Eq. (5), $\bar{\chi}$ represents the zonal mean mixing ratio of the tracer, $\nabla \cdot \boldsymbol{M}$ is the eddy transport term (as in Andrews et al., 1987, Eq. 9.4.13) and $P-L$ is the chemical production minus loss rate. Averaging over the tropics and for a given pressure level, these equations state that the changes in tropical mean temperature or tracer concentration arise from the combined effects of meridional and vertical advection by the residual mean circulation (that is, mean meridional transport to/from the extra-tropics and upwelling acting on the background vertical gradient), eddy transport and diabatic heating in the case of temperature or chemical sources/sinks for tracers. Equations (4) and (5) form the basis for our analysis of temperature and tracer coupling with 

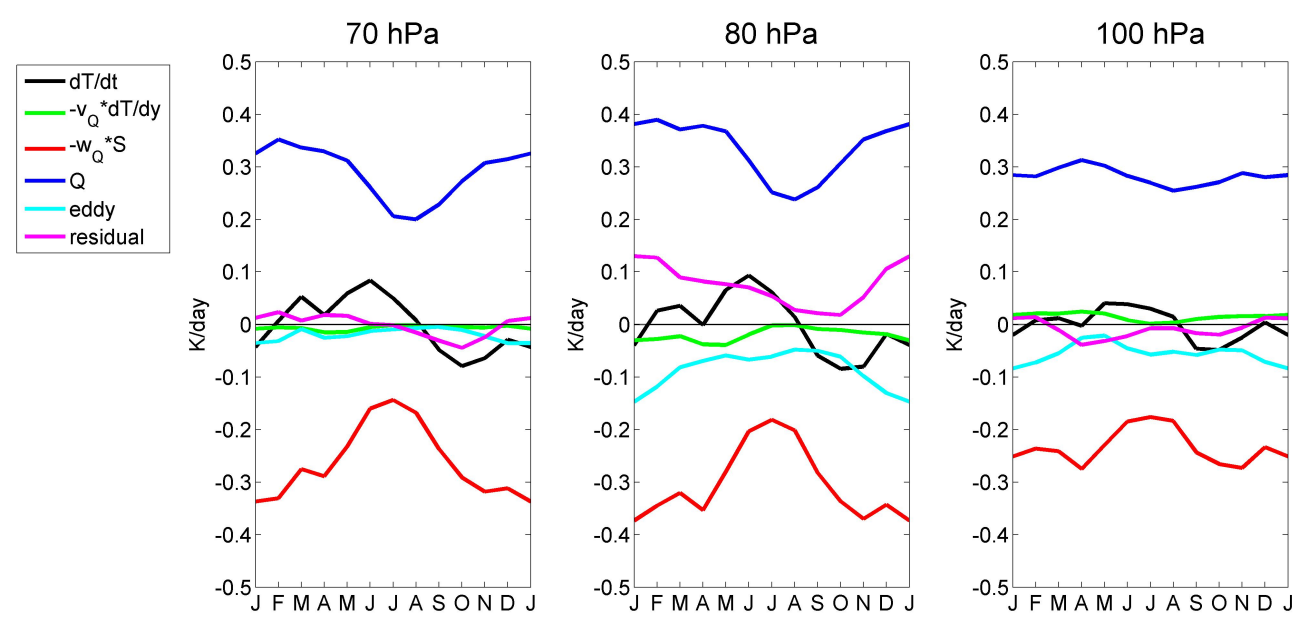

Fig. 5. Mean seasonal cycle (monthly means for the period 2005-2010) of the terms in the thermodynamic equation (Eq. 4) averaged over $18^{\circ} \mathrm{N}-\mathrm{S}$ for the three pressure levels indicated. The residual is defined as the difference between the tendency and the sum of all the explicitly evaluated terms $\left(\mathrm{K} \mathrm{day}^{-1}\right)$.

mean tropical upwelling, and we focus separately on the seasonal cycle and sub-seasonal variations seen in Figs. 1 and 3.

\subsection{Seasonal cycles}

In order to evaluate the relative contribution of the different forcings to the seasonal cycles of temperature, ozone and $\mathrm{CO}$, we analyze the monthly means for the entire period (2005-2010) of all the terms in Eqs. (4) and (5). Figure 5 shows the seasonal average thermodynamic balance, after averaging Eq. (4) over a latitudinal band of $18^{\circ} \mathrm{N}-\mathrm{S}$, using the estimate of $\bar{w}_{Q}^{*}$ for mean upwelling. $\bar{Q}$ is calculated from the radiative heating code as described in Sect. 2.2.

The primary thermodynamic balance in the tropical lower stratosphere in Fig. 5 is between upwelling (adiabatic cooling) and diabatic heating (i.e. $\bar{w}_{Q}^{*} S \sim \bar{Q}$ ). The temperature tendency is a relatively small component of the balance, and the meridional advection term is negligible. We have included the eddy term in Fig. 5 (derived from the ERAInterim eddy fields), even though it is not used to compute $\bar{w}_{Q}^{*}$, as explained in Sect. 2.2. This term shows a maximum in the tropics near $80 \mathrm{hPa}$, which is mainly associated with the vertical convergence of the vertical eddy heat flux $\left(\overline{w^{\prime} T^{\prime}}\right)$ in Eq. (4). There are small residuals in Fig. 5 at $70 \mathrm{hPa}$ (where the eddy term is almost zero) and $100 \mathrm{hPa}$, indicating that the magnitude and seasonality of the computed estimate $\bar{w}_{Q}^{*}$ are consistent with the total thermodynamic balance at these levels. On the other hand, at $80 \mathrm{hPa}$ the residual approximately mirrors the relatively large negative eddy term. This implies that, as a result of neglecting the eddies in the thermodynamic equation, the magnitude of the computed upwelling is overestimated at $80 \mathrm{hPa}$ (by about $\sim 0.15 \mathrm{~mm} \mathrm{~s}^{-1}$ in the annual mean). Nevertheless, it should be borne in mind that the vertical eddy heat flux $\left(\overline{w^{\prime} T^{\prime}}\right)$ in Fig. 5 is likely subject to large uncertainties associated with the reanalysis eddy ver- tical velocity anomalies. The overall balances are similar if $\bar{w}_{m}^{*}$ or $\bar{w}^{*}$ are used instead of $\bar{w}_{Q}^{*}$, although larger residuals are derived when using $\bar{w}^{*}$ (especially at $100 \mathrm{hPa}$ ). The interpretation of the $\bar{w}_{Q}^{*} S \sim \bar{Q}$ balance is that upwelling forces tropical temperatures below radiative equilibrium $\left(\bar{T}_{\text {eq }}\right)$, and the atmosphere responds locally by longwave radiative heating. This radiative heating is due primarily to the effects of longwave forcing by ozone and $\mathrm{CO}_{2}$ (e.g. Thuburn and Craig, 2000; Gettelman et al., 2004), and $\bar{Q}$ can be reasonably approximated in this region by Newtonian cooling: $\bar{Q} \sim-\alpha_{\text {rad }}\left(\bar{T}-\bar{T}_{\text {eq }}\right)$, where $\alpha_{\text {rad }}$ is an inverse radiative relaxation timescale and $\bar{T}_{\text {eq }}$ is a background radiative equilibrium temperature. The seasonal variations in upwelling are echoed in approximately mirror image variations in $\bar{Q}$ at 70 and $80 \mathrm{hPa}$ in Fig. 5: weaker NH summer upwelling results in warmer temperatures and weaker radiative heating, and there is a slight delay in $\bar{Q}$ compared to $\bar{w}^{*}$ because of the $\sim 1-2$ month radiative relaxation timescale in the lower stratosphere. The longer relaxation timescales ( $\operatorname{smaller} \alpha_{\text {rad }}$ ) also result in relatively larger temperature variations for these pressure levels (cf. Randel et al., 2002). Although the seasonal variation in upwelling at $100 \mathrm{hPa}$ is around a factor of 2-2.5 (Fig. 3), the upwelling transport term in Fig. 5 at this level varies only $\sim 1.5$. This is because there is a seasonal cycle in static stability $S$ at $100 \mathrm{hPa}$ (with NH summer values $\sim 1.5$ times larger than winter), so that the quantity $\bar{w}_{Q}^{*} S$ varies much less than $\bar{w}_{Q}^{*}$ alone. This partial compensation results in smaller seasonal variations in $\bar{Q}$ and $\partial \bar{T} / \partial t$ at $100 \mathrm{hPa}$ compared to higher levels.

Figure 6 shows the analogous calculations for the zonal average ozone continuity equation (Eq. (5)), where the explicitly evaluated terms include the tendency of the ozone mixing ratio, the meridional advection, and the upwelling forcing. We have also included an ozone photochemical production 

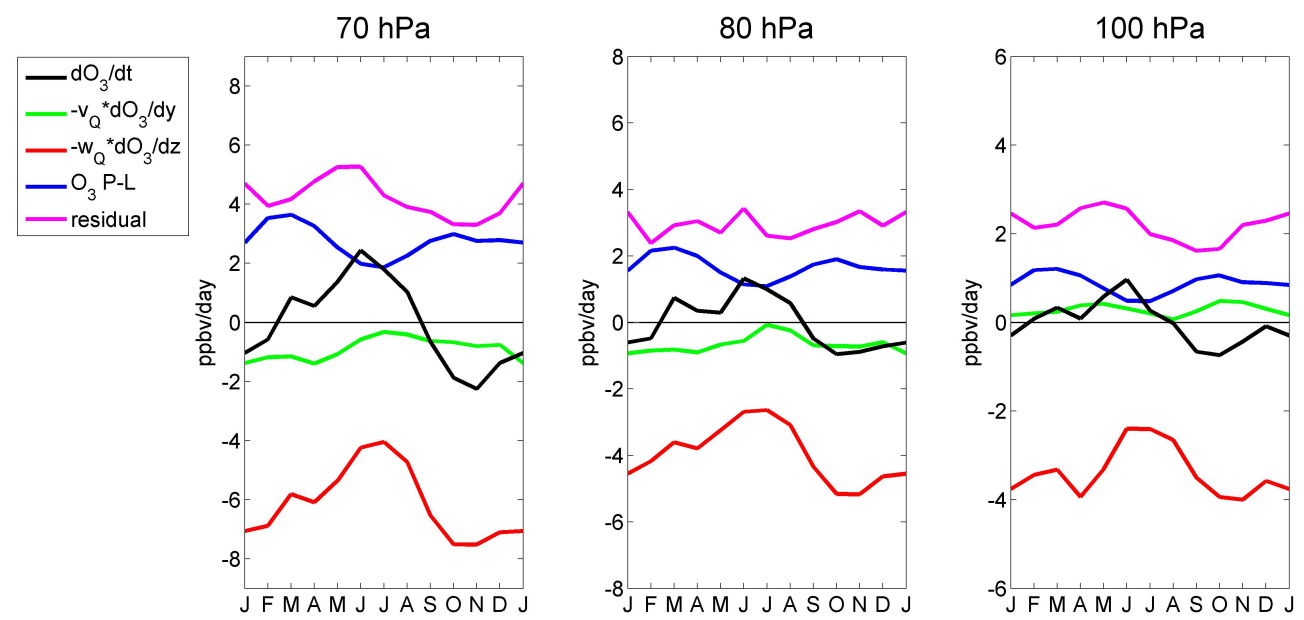

Fig. 6. Mean seasonal cycle for the period 2005-2010 of the terms in the continuity equation for ozone concentration (Eq. 5) averaged over $18^{\circ} \mathrm{N}-\mathrm{S}$ at the indicated levels (ppbv day ${ }^{-1}$ ).

minus loss term ( $P-L$ in Eq. (5)), obtained from a long-term simulation using the WACCM (Whole Atmosphere Community Climate Model) chemistry-climate model (Doug Kinnison 2011, personal communication). The photochemical production in Fig. 6 shows a weak semi-annual cycle, following the solar declination in the tropics. Figure 6 also shows the residual of the calculated balance, which is a relatively large positive term at each level $\left(\sim 4-5 \mathrm{ppbv}^{-1 a y^{-1}}\right.$ at $\left.70 \mathrm{hPa}\right)$, and represents eddy transport terms (not explicitly computed in these calculations due to the coarse horizontal resolution of the tracer observations) plus uncertainties in the rest of the terms. The presence of a significant residual in these calculations is consistent with the importance of eddy transport into the tropics for the ozone budget, as suggested previously by Konopka et al. (2010) using a three-dimensional Lagrangian transport model. We note that the residuals in Fig. 6 do not show large annual variations and, particularly at $70 \mathrm{hPa}$, the seasonality in the upwelling term is dominant.

The overall seasonal behavior of the ozone budget (Fig. 6) highlights tropical upwelling as a primary forcing term, with the ozone tendency closely following the upwelling term. There is strong similarity to the seasonal thermodynamic balance (Fig. 5), and the dominant role of upwelling in both balances suggests that the in-phase annual cycles in ozone and temperature seen in Fig. 1 are linked as a response to the seasonal variation in upwelling. As in the case of temperature, the upwelling forcing on ozone has a smaller seasonal cycle at $100 \mathrm{hPa}$ compared to the higher levels due to the partial cancellation between the annual cycles of tropical upwelling (largest during $\mathrm{NH}$ winter) and ozone vertical gradient (smallest during NH winter; result not shown). In fact, the latter is very similar to the seasonal cycle of the static stability at this level.

The seasonal balance for zonal average $\mathrm{CO}$ at $70 \mathrm{hPa}$ is shown in Fig. 7. This is the level where the relative verti-

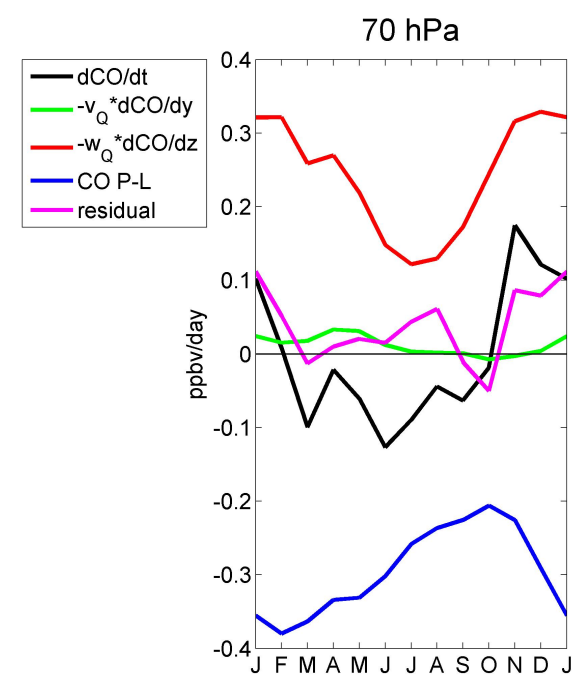

Fig. 7. Mean seasonal cycle (2005-2010) of the terms in the CO continuity equation at $70 \mathrm{hPa}$ averaged over $18^{\circ} \mathrm{N}-\mathrm{S}\left(\mathrm{ppbv}_{\text {day }}{ }^{-1}\right)$.

cal gradient in background $\mathrm{CO}$ is largest, and so it is anticipated that the vertical transport has a large influence on observed variability. In these budget calculations we have also included a chemical production minus loss term in Eq. (5) for $\mathrm{CO}$; the loss is approximated by $\beta \cdot \mathrm{CO}$, with $\beta$ an inverse chemical damping timescale of 100 days (estimated from WACCM data), and a small chemical production term is also obtained from WACCM. The time average budget in Fig. 7 reflects a balance between $\mathrm{CO}$ increase due to vertical transport and decrease due to photochemical loss. A seasonal variation of approximately a factor of 2 is found for the contribution of upwelling to the $\mathrm{CO}$ budget in Fig. 7 (which simply follows the annual cycle in upwelling), and the observed CO tendency closely follows this seasonality. The photochemical loss approximately mirrors the upwelling 
tendency, with a time lag of several months. The calculated residual is a relatively small component of the $\mathrm{CO}$ balance for most months, suggesting a relatively simple balance for $\mathrm{CO}$ in the tropical lower stratosphere. There is a larger residual during November-January in Fig. 7, which may be due to unresolved eddy transport effects or to uncertainties in calculations for the resolved terms. The seasonal $\mathrm{CO}$ budget at $100 \mathrm{hPa}$ (not shown) is dominated by the semi-annual cycle in $\mathrm{CO}$ concentrations seen in Fig. 1, and is somewhat more complicated than the $70 \mathrm{hPa}$ results in Fig. 7. The characteristic double peak in $\mathrm{CO}$ in the tropical upper troposphere (seen for $100 \mathrm{hPa}$ data in Fig. 1) is associated with emissions from biomass burning before the rain seasons, coupled with the semi-annual cycle in near-equatorial convection (Folkins et al., 2006; Schoeberl et al. 2006; Liu et al, 2007). The overall smaller residuals obtained in the $\mathrm{CO}$ balance compared to ozone, suggest that eddy mixing makes a more modest contribution to the $\mathrm{CO}$ tropical budget. Reduced horizontal eddy transport for $\mathrm{CO}$ is consistent with the relatively smaller meridional gradients in this tracer compared to ozone (as pointed out in Ploeger et al., 2012).

\subsection{Sub-seasonal variability}

The time series in Fig. 1 reveal correlated variations between temperatures and tracers at timescales shorter than the annual cycle. Sub-seasonal variations in upwelling (as seen in Fig. 3) are one likely source for such correlated variability, and here we investigate the links between upwelling and tracer variations on sub-seasonal timescales. In these analyses we focus on comparing time tendencies of temperature and tracers (i.e. $\partial \bar{T} / \partial t, \partial \overline{\mathrm{O}_{3}} / \partial t$ and $\partial \overline{\mathrm{CO}} / \partial t$ ) with the various estimates of upwelling, following the expected relationships based on Eqs. (4) and (5).

Assuming the idealized case where for transient variations the vertical velocity terms dominate the thermodynamic and continuity equations (i.e. neglecting meridional advection, eddy transport, radiative or chemical forcing terms), Eqs. (4) and (5) reduce to:

$$
\begin{array}{r}
\frac{\partial \bar{T}}{\partial t}=-\bar{w}^{*} S \\
\frac{\partial \bar{\chi}}{\partial t}=-\bar{w}^{*} \bar{\chi}_{z}
\end{array}
$$

with $\bar{\chi}_{z} \equiv \partial \bar{\chi} / \partial z$. These simplified equations directly relate the tendencies to $\bar{w}^{*}$, and imply that for these idealized conditions (where $\bar{w}^{*}$ dominates the transport) the temperature and tracer tendencies are closely linked:

$$
\left(\frac{\partial \bar{\chi}}{\partial t}\right) /\left(\frac{\partial \bar{T}}{\partial t}\right)=\bar{\chi}_{z} / S \sim \text { constant }
$$

(and similarly, the ratio of tendencies for different tracers are related by the ratios of their respective background vertical gradients). The ratio $\bar{\chi}_{z} / S$ can be considered approximately

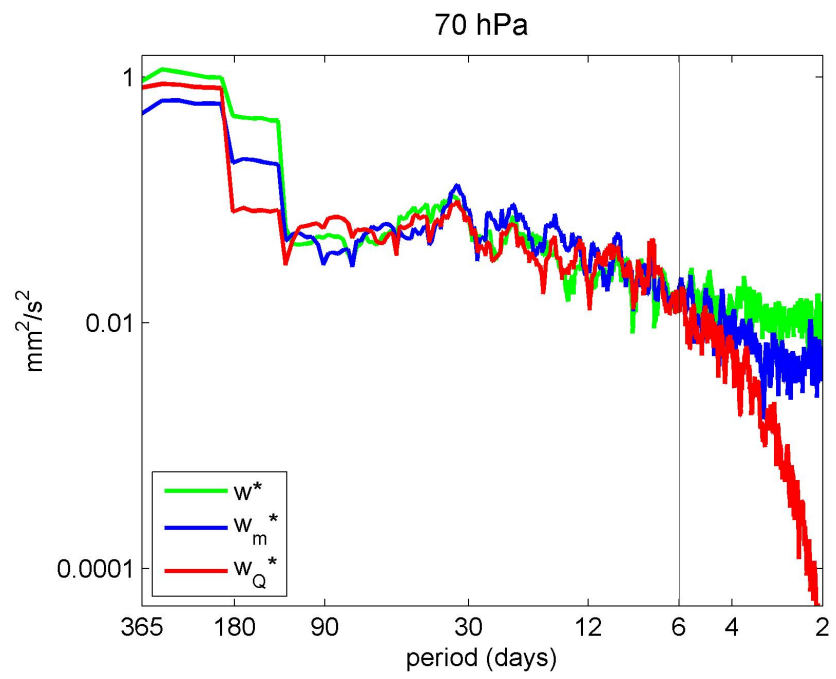

Fig. 8. Power spectra of the three upwelling estimates at $70 \mathrm{hPa}$ as a function of log-frequency. An 11-point running mean was applied to the spectra $\left(\mathrm{mm}^{2} \mathrm{~s}^{-2}\right)$.

constant, given that the tracer vertical gradients and the static stability are nearly stationary on sub-seasonal timescales. We note that the strong relationships with upwelling are most likely to occur in the region of largest background vertical gradients (i.e., near $70 \mathrm{hPa}$ for ozone and $\mathrm{CO}$ ).

In the following analyses we focus on sub-seasonal variations associated with timescales shorter than one year and longer than 6 days, isolated by harmonic analysis of the respective time series. The 6-day frequency cutoff is intended to remove the day-to-day variability in the different upwelling estimates, which shows large differences among the different calculations and little coherence with temperatures or tracers. In fact, the correlations in Fig. 4 increase by about $\sim 0.1$ if these high frequencies are filtered out. Figure 8 shows the power spectra of the three upwelling estimates at $70 \mathrm{hPa}$ to illustrate the very different spectral behavior of the data at the highest frequencies, motivating the high frequency (6-day) cutoff. Our detailed results are not sensitive to the exact choice of high frequency cutoff.

Figure 9 shows standardized anomalies of the temperature, ozone and $\mathrm{CO}$ tendencies at $70 \mathrm{hPa}$, together with corresponding time series of upwelling for a period of one year (2010), in order to focus on detailed sub-seasonal behavior. Visual inspection of Fig. 9 shows coherent variations between $\partial \bar{T} / \partial t$ and $\partial \overline{\mathrm{O}_{3}} / \partial t$ at $70 \mathrm{hPa}$, and somewhat lower agreement of $\partial \overline{\mathrm{CO}} / \partial t$ with the other two series. Time series of the upwelling estimates show highly coherent variations, which often show good correspondence with the temperature and tracer tendencies.

The correlations between sub-seasonal variations in upwelling and tendencies of temperature and tracers are shown in Fig. 10 (calculated from data over all years 2005-2010), for altitude levels over $100-30 \mathrm{hPa}$; these include results for 


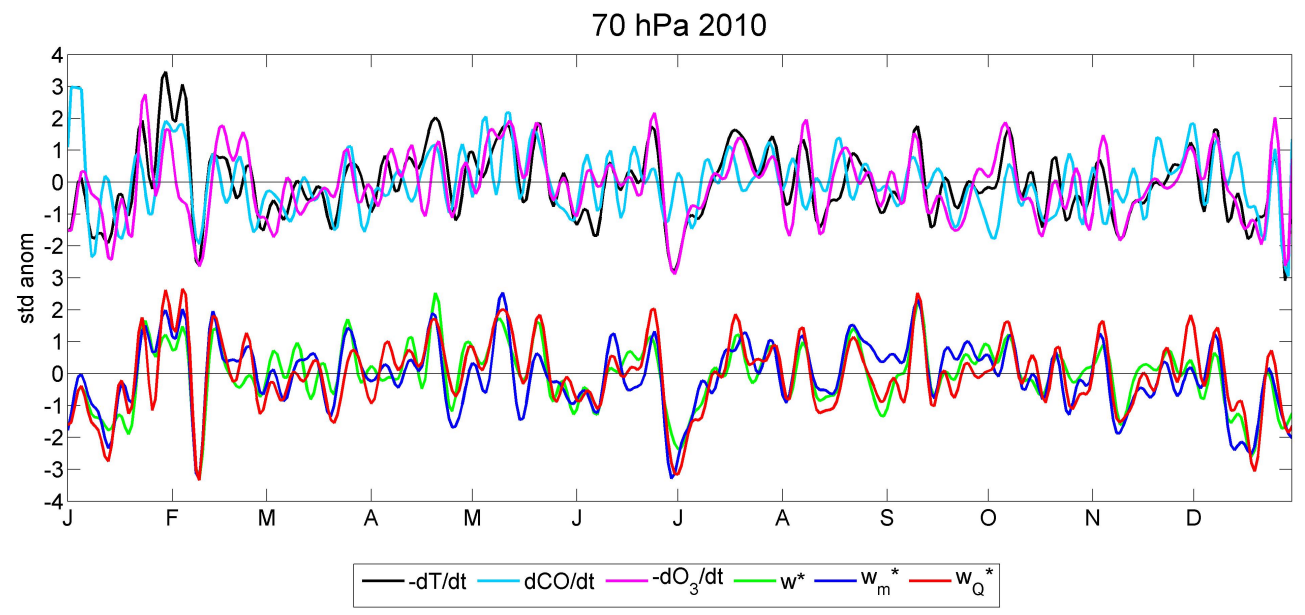

Fig. 9. Top curves show time series for the year 2010 of standardized anomalies of temperature (black), ozone (purple) and CO (light blue) tendencies. Bottom curves show the three estimates of upwelling: $\bar{w}^{*}$ (green), $\bar{w}_{m}^{*}$ (blue) and $\bar{w}_{Q}^{*}$ (red) at $70 \mathrm{hPa}$. Temperature and ozone tendencies are plotted on a reversed scale. All series are filtered to remove timescales $\geq 1 \mathrm{yr}$ and $\leq 6$ days.

each of the three different upwelling estimates. Taking into account the appropriate degrees of freedom for these data, correlations above 0.12 are significant at the $99 \%$ level.

Temperature tendencies (Fig. 10a) show highly significant correlations with each of the upwelling estimates, with small variations with altitude. Very high correlations $(>0.8)$ are found for $\bar{w}_{Q}^{*}$, and this is expected as $\bar{w}_{Q}^{*}$ is calculated using thermodynamic balance with observed $\partial \bar{T} / \partial t$. Correlations of $\partial \bar{T} / \partial t$ with $\bar{w}_{m}^{*}$ and $\bar{w}^{*}$ are somewhat lower but still highly significant $(\sim 0.7)$, and this enhances confidence in these estimates.

Correlations between ozone tendencies and upwelling (Fig. 10b) show overall significant values, with similar results for the different upwelling estimates. The largest correlations are found at $70 \mathrm{hPa}$ and above, and this is reasonable as the background vertical gradient of ozone is larger at these levels. For CO tendencies (Fig. 10c), the correlations are somewhat lower compared to ozone, with a different vertical structure that shows largest correlations at 100 and $70 \mathrm{hPa}$ and almost zero at $50 \mathrm{hPa}$. It is important to note that due to the $\sim 4.5 \mathrm{~km}$ vertical resolution of MLS CO observations, particular caution should be taken when drawing conclusions based upon the detailed vertical structure of $\mathrm{CO}$. Also, near $50 \mathrm{hPa}$ the absolute values of $\mathrm{CO}$ mixing ratio are very small ( $\sim 10-20 \mathrm{ppbv})$ and hence it is likely that measurements at these upper levels are subject to larger relative uncertainties. Note that MLS measurements currently constitute the only available observational dataset of $\mathrm{CO}$ with daily temporal resolution in this region.

Further confirmation that sub-seasonal variations in upwelling make an important contribution to sub-seasonal variability in the tracer fields is provided by comparing the observed ratios of tracer versus temperature tendencies to the theoretical estimate (i.e. time-mean $\overline{\chi_{z}} / S$, Eq. 8). Fig- ure 11a shows a scatter diagram of $\partial \bar{T} / \partial t$ versus $\partial \overline{\mathrm{O}_{3}} / \partial t$ for the $70 \mathrm{hPa}$ data (as shown in Fig. 9 but for the entire period), showing a significantly correlated distribution $(r=$ 0.63 ) with a linear slope of $20.4 \pm 1.9 \mathrm{ppbv} \mathrm{K}^{-1}$ (estimated using least squares linear regression, including a 2-sigma uncertainty level). This observed slope compares quite well with the theoretical value $\bar{\chi} / S=23.4 \mathrm{ppbv} \mathrm{K}^{-1}$ at $70 \mathrm{hPa}$, indicating that the observed variations are not too far from the case of variability controlled by upwelling via Eqs. (6)-(8). Figure $11 \mathrm{~b}$ shows a similar diagram for $\partial \bar{T} / \partial t$ versus $\partial \overline{\mathrm{CO}} / \partial t$ statistics at $70 \mathrm{hPa}$. In this case there is a larger dispersion of the scattered points and the correlation is lower $(r=-0.47)$. This could be at least partly related to the coarser vertical resolution of $\mathrm{CO}$ observations discussed above. The slope given by Eq. (8) for this tracer is $-0.90 \mathrm{ppbv} \mathrm{K}^{-1}$, and the linear regression gives a similar slope of $-1.14 \pm 0.16 \mathrm{ppbv} \mathrm{K}^{-1}$. Overall the observed slopes for both ozone and CO in Fig. 11 are reasonably similar to calculations based on the highly idealized situation where upwelling is the dominant forcing mechanism for sub-seasonal variability (although the theoretical slopes lie outside of the 2-sigma (95\%) bounds of the regression slopes in both cases, which could result from data uncertainties or additional forcing mechanisms). These results are consistent with the coherent fluctuations observed between upwelling and tracer tendencies in Figs. 9 and 10.

It is worth noting that the lines in Fig. 11 have a smaller slope than what a visual examination of the scattered data points suggests. A simple analysis with synthetic data was made to understand this discrepancy. We constructed two linearly related variables $(\mathrm{y}=\mathrm{mx})$ and added some noise (normally distributed random variations) to each variable independently. Inspection of the scatter diagrams for different noise levels revealed that the actual slope $(=\mathrm{m}$ by construction) coincides with the visual slope only if the amount of 

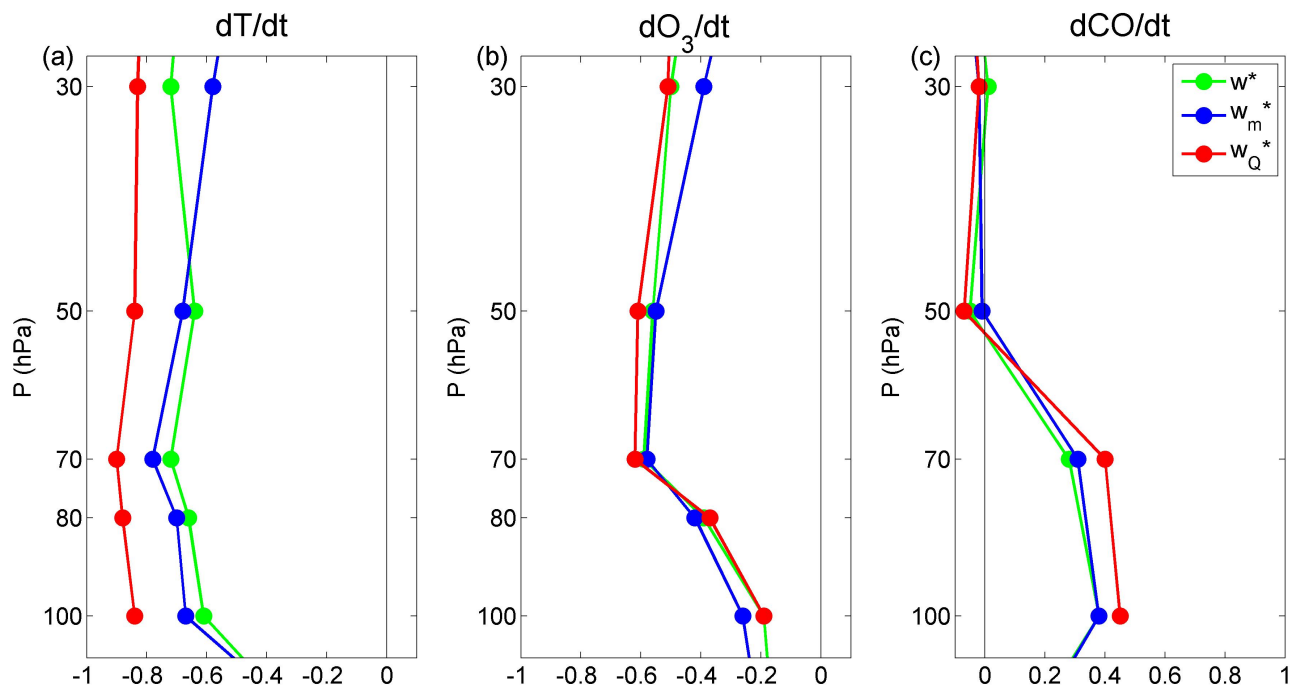

Fig. 10. Linear correlations as a function of pressure between the upwelling estimates and temperature (a), ozone (b) and CO (c) tendencies. Results are shown for the three estimates $\left(\bar{w}^{*}\right.$ in green, $\bar{w}_{m}^{*}$ in blue and $\bar{w}_{Q}^{*}$ in red). The correlations are calculated between the sub-seasonal time series ( 6 days $<$ periods $<1$ yr) as shown in Fig. 10 but for the 6 -yr long (2005-2010) time series. The $99 \%$ significance level is $\alpha \sim 0.12$.
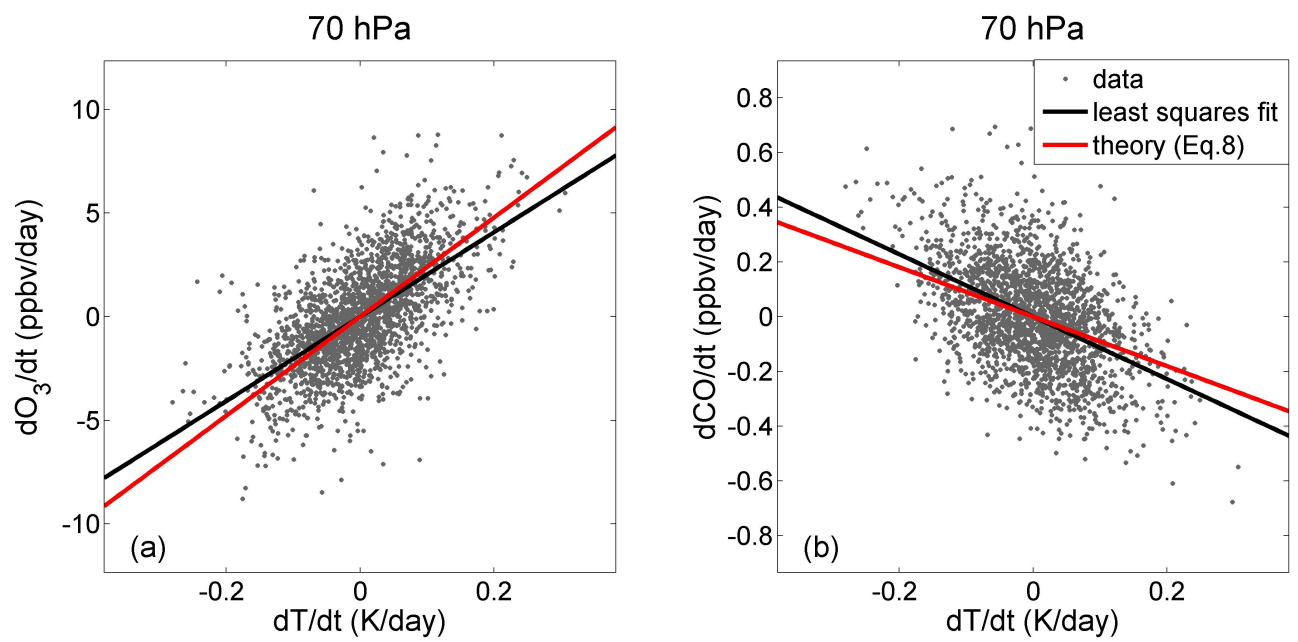

Fig. 11. Scatter diagrams of (a) ozone and (b) CO tendency versus temperature tendency at $70 \mathrm{hPa}$. The dots correspond to sub-seasonal filtered data as in Figs. 9 and 10. The black line is the least squares linear fitting of the data and the red line is the estimated slope using the simplified relation $\left(\bar{\chi}_{z} / S\right)$ from Eq. (8).

noise in both variables is comparable; the actual slope is smaller (larger) than the visual slope if the noise is larger (smaller) in $y$ than in $x$. Accordingly, the discrepancy in Fig. 11 can be understood if there are larger uncertainties in MLS tracer tendencies (y axis) than in ERA-Interim temperature tendencies (x-axis). Furthermore, this exercise proved that, under this assumption, the slope given by the least squares regression of $\partial \bar{\chi} / \partial t$ onto $\partial \bar{T} / \partial t$ (as shown in Fig. 11) is an accurate estimate of the actual slope of the data.

Note that less than $50 \%$ of variance in the tendencies is explained by upwelling for both tracers, so that it is not possible to state that upwelling is the dominant control mech- anism of sub-seasonal tracer variability. Instead, the results should be interpreted as a statistical proof that the suggested physical mechanism accounts for a significant fraction of the observed tracer variability. Overall, the observed statistically significant correlations of tropical upwelling with temperature and tracer tendencies, together with the reasonable agreement between the slope of the tracer versus temperature tendencies and predictions from the idealized balance in Eqs. (6)-(8), are strong evidence that sub-seasonal variations in upwelling make an important contribution to corresponding variability in temperature, ozone and $\mathrm{CO}$ in the tropical 
lower stratosphere, in particular at the levels where vertical gradients are larger.

\section{Summary and discussion}

Tropical upwelling is a key aspect of the global stratospheric circulation, but fundamental aspects such as forcing mechanisms and temporal variability are poorly understood. In this study we evaluated the variability and quality of zonal average tropical upwelling estimates derived from different techniques $\left(\bar{w}^{*}, \bar{w}_{m}^{*}\right.$ and $\left.\bar{w}_{Q}^{*}\right)$. Overall there is good agreement among the three (independent) estimates, although the magnitude of $\bar{w}^{*}$ from ERA-Interim is somewhat larger than the other estimates, especially at $100 \mathrm{hPa}$. This consistency, particularly between $\bar{w}_{m}^{*}$ and $\bar{w}_{Q}^{*}$, reflected in Figs. 3 and 4 , is the primary evidence of the accuracy of the estimates. Furthermore, sub-seasonal variations are correlated with both temperatures and tracer concentrations in the tropical lower stratosphere. This result implies that sub-seasonal variations in the upwelling estimates reflect - at least to the extent quantified by the correlations in Figs. 4 and 10 - actual fluctuations in the atmosphere, and hence gives further confidence in the variability of the indirect upwelling estimates on fast timescales. For instance, the reasonable agreement of $\bar{w}_{m}^{*}$ with the other estimates suggests the possibility of analyzing the terms in the momentum balance to understand dynamical forcing mechanisms of tropical upwelling at sub-seasonal timescales.

Time series for 2005-2010 in Fig. 1 show coherence among temperature, ozone and $\mathrm{CO}$ in the tropical lower stratosphere, for both seasonal and sub-seasonal timescales. Because ozone, $\mathrm{CO}$ and (potential) temperature all exhibit enhanced vertical gradients in the tropical lower stratosphere, the observed relationships suggest that upwelling plays a central role in producing this coherent behavior. We have evaluated explicitly the zonal mean thermodynamic and tracer continuity equations to quantify the influence of upwelling, focusing separately on seasonal and sub-seasonal timescales. The seasonal calculations (based on monthly averaged data) show that upwelling is a dominant term in all cases (Figs. 5, 6 and 7), so that the seasonal cycle in upwelling (maximum during $\mathrm{NH}$ winter) is a simple mechanism responsible for the coupled seasonal variations in temperature, ozone and $\mathrm{CO}$. This summary statement is most applicable for altitudes where the background gradients are strongest (i.e. near $70 \mathrm{hPa}$ for ozone and $\mathrm{CO}$ ).

An important caveat is that the seasonal ozone and $\mathrm{CO}$ budgets in our calculations (Figs. 6 and 7) have significant residuals, which are likely due to eddy transport not resolved in our analyses plus uncertainties in the resolved terms. The importance of eddy transport for ozone in the tropical lower stratosphere has been suggested by Konopka et al. (2009, 2010) and Ploeger et al. (2012), hereafter KP. The results of KP deserve further discussion. Their calculations, based on analysis of Lagrangian trajectories on isentropic levels, suggest that the seasonal cycle of ozone in the tropical lower stratosphere is primarily a response to horizontal transport (in-mixing), rather than upwelling. Our results, based on TEM budget calculations on altitude (log-pressure) surfaces (Fig. 6), clearly highlight the dominance of vertical transport for the ozone seasonal cycle. Understanding the very different results from these distinct calculations will require further analysis, and here we just briefly discuss some of the possible reasons for this discrepancy. One relevant difference between $\mathrm{KP}$ and the present work is the choice of the vertical coordinate. Konopka et al. (2009) show that the amplitude of the seasonal cycle in ozone is reduced by more than $50 \%$ when analyzed on isentropic levels. This is because of the strong correlation between temperature and ozone (see Fig. 1), so that the annual cycle in potential temperature in this region is almost in phase with ozone. However, it is precisely this common variability between tracers and temperature that we are interested in, which we argue arises mainly from the effect of tropical upwelling. Because the seasonal variation in the isentropes is a response to upwelling (combined with corresponding diabatic forcing), understanding the movement of the isentropes is an integral part of the coupled problem. Another fundamental difference between KP and our analyses is the Lagrangian versus TEM approach. In the present work the TEM framework is used to investigate the origin of the seasonality in ozone as revealed by (Eulerian) observations. On the other hand, Lagrangian calculations provide values of ozone concentrations from material derivatives integrated along parcel trajectories. It is possible that the results are only apparently contrasting because of the different perspective (e.g. high-ozone air in-mixed at lower levels and then transported upward by tropical upwelling will be considered horizontal transport in the Lagrangian view and vertical advection in the TEM calculations). Ploeger et al. (2012) point out that because of these differences the comparison is not straight-forward, and we remark here the importance of bearing in mind the characteristics of each analysis when interpreting the results. Indeed, these constitute very interesting issues to be explored in future studies in order to improve our understanding of tracer variability and transport processes in the tropical lower stratosphere.

Finally, sub-seasonal variations in upwelling show statistically significant correlations with temperature and tracer tendencies. In addition, the slopes of the observed ratios of temperature versus ozone and $\mathrm{CO}$ tendencies (Fig. 11) are relatively close to the idealized situation where variability is primarily controlled by fluctuations in upwelling (Eqs. 68). This proves that variability in upwelling explains a significant fraction of the transient fluctuations in ozone and $\mathrm{CO}$ at levels with large vertical gradients above the tropical tropopause. These results for sub-seasonal timescales are also consistent with our findings for the respective seasonal cycles, and highlight the important role of tropical 
upwelling in forcing tracer variability across a broad range of timescales.

Acknowledgements. We thank Mijeong Park for providing MLS data, Fei Wu for calculating the radiative heating rates and Doug Kinnison for providing the chemical production and loss rates for ozone and CO from WACCM. The ECMWF provided the ERA-Interim data used in this work. We thank John Bergman and Rolando R. Garcia for constructive comments on the manuscript. We also thank four anonymous referees for their helpful reviews. This work was partially supported under the NASA Aura Science Program. Most of the work has been carried out at NCAR during visits of Marta Abalos funded by the FPI program from the Spanish Ministry of Science and Innovation. The National Center for Atmospheric Research is operated by the University Corporation for Atmospheric Research, under sponsorship of the National Science Foundation.

Edited by: P. Haynes

\section{References}

Andrews, D. G., Holton, J. R., and Leovy, C. B.: Middle Atmosphere Dynamics, Academic Press, Orlando, Florida, 489 pp., 1987.

Bernath, P. F., McElroy, C. T., Abrams, M. C., Boone, C. D., Butler, M., Camy-Peyret, C., Carleer, M., Clerbaux, C., Coheur, P. F., Colin, R., DeCola, P., DeMazière, M., Drummond, J. R., Dufour, D., Evans, W. F. J., Fast, H., Fussen, D., Gilbert, K., Jennings, D. E., Llewellyn, E. J., Lowe, R. P., Mahieu, E., McConnell, J. C., McHugh, M., McLeod, S. D., Michaud, R., Midwinter, C., Nassar, R., Nichitiu, F., Nowlan, C., Rinsland, C. P., Rochon, Y. J., Rowlands, N., Semeniuk, K., Simon, P., Skelton, R., Sloan, J. J., Soucy, M.-A., Strong, K., Tremblay, P., Turnbull, D., Walker, K. A., Walkty, I., Wardle, D. A., Wehrle, V., Zander, R., and Zou, J.: Atmospheric Chemistry Experiment (ACE): Mission overview, Geophys. Res. Lett., 32, L15S01, doi:10.1029/2005GL022386, 2005.

Brewer, A. W.: Evidence for a world circulation provided by the measurements of helium and water vapour distribution in the stratosphere, Q. J. Roy. Meteor. Soc., 75, 351-363, 1949.

Calvo, N. and Garcia, R. R.: Wave forcing of the tropical upwelling in the lower stratosphere under increasing concentrations of greenhouse gases, J. Atmos. Sci., 66, 3184-3196, 2009.

Chae, J. H. and Sherwood, S. C.: Annual temperature cycle of the tropical tropopause: A simple model study, J. Geophys. Res., 112, D19111, doi:10.1029/2006JD007956, 2007.

Dee, D. P., Uppala, S. M., Simmons, A. J., Berrisford, P., Poli, P., Kobayashi, S., Andrae, U., Balmaseda, M. A., Balsamo, G., Bauer, P., Bechtold, P., Beljaars, A. C. M., van de Berg, L., Bidlot, J., Bormann, N., Delsol, C., Dragani, R., Fuentes, M., Geer, A. J., Haimberger, L., Healy, S. B., Hersbach, H., Hólm, E. V., Isaksen, L., Kållberg, P., Köhler, M., Matricardi, M., McNally, A. P., Monge-Sanz, B. M., Morcrette, J.-J., Park, B.-K., Peubey, C., de Rosnay, P., Tavolato, C., Thépaut, J.-N., and Vitart, F.: The ERA-interim reanalysis: configuration and performance of the data assimilation system, Q. J. Roy. Meteor. Soc., 137, 553-597, doi:10.1002/qj.828, 2011.
Dobson, G. M. B.: Origin and distribution of the polyatomic molecules in the atmosphere, Proc. R. Soc. A, 236, 187-193, doi:10.1098/rspa.1956.0127, 1956.

Folkins, I., Bernath, P., Boone, C., Lesins, G., Livesey, N., Thompson, A. M., Walker, K., and Witte, J. C.: Seasonal cycles of $\mathrm{O}_{3}$, $\mathrm{CO}$, and convective outflow at the tropical tropopause, Geophys. Res. Lett., 33, L16802, doi:10.1029/2006GL026602, 2006.

Froidevaux, L., Livesey, N. J., Read, W. G., Jiang, Y. B., Jimenez, C., Filipiak, M. J., Schwartz, M. J., Santee, M. L., Pumphrey, H. C., Jiang, J. H., Wu, D. L., Manney, G. L., Drouin, B. J., Waters, J. W., Fetzer, E. J., Bernath, P. F., Boone, C. D., Walker, K. A., Jucks, K. W., Toon, G. C., Margitan, J.,J., Sen, B., Webster, C. R., Christensen, L. E., Elkins, J. W., Atlas, E., Lueb, R. A., and Hendershot, R.: Early validation analyses of atmospheric profiles from EOS MLS on the Aura satellite, IEEE Trans. Geosci. Remote Sens., 44, 1106-1121, 2006.

Fueglistaler, S., Dessler, A. E., Dunkerton, T. J., Folkins, I., Fu, Q., and Mote, P. W.: Tropical tropopause layer, Rev. Geophys., 47, RG1004, doi:10.1029/2008RG000267, 2009a.

Fueglistaler, S., Legras, B., Beljaars, A., Morcrette, J. J., Simmons, A., Tompkins, A. M., and Uppala, S.: The diabatic heat budget of the upper troposphere and lower/mid stratosphere in ECMWF reanalysis, Q. J. Roy. Meteor. Soc., 135, 21-37, doi:10.1002/qj.361, 2009b.

Fueglistaler, S., Haynes, P. H., and Forster, P. M.: The annual cycle in lower stratospheric temperatures revisited, Atmos. Chem. Phys., 11, 3701-3711, doi:10.5194/acp-11-3701-2011, 2011.

Garcia, R. R. and Randel, W. J.: Acceleration of the Brewer-Dobson circulation due to increases in greenhouse gases, J. Atmos. Sci., 65, 2731-2739, 2008.

Gettelman, A., Forster, P., Fujiwara, M., Fu, Q., Vömel, H., Gohar, L., Johason, C., and Ammerman, M.: The radiation balance of the tropical tropopause layer, J. Geophys. Res., 109, D07103, doi:10.1029/2003JD004190, 2004.

Gille, J. C., Lyjak, L. V., and Smith, A. K.: The global residual mean circulation in the middle atmosphere for the northern winter period, J. Atmos. Sci., 44, 1437-1452, 1987.

Iwasaki, T., Hamada, H., and Miyazaki, K.: Comparisons of Brewer-Dobson circulations diagnosed from reanalyses, J. Meteor. Soc. Jpn., 87, 997-1006, 2009.

Konopka, P., Grooß, J.-U., Ploeger, F., and Müller, R.: Annual cycle of horizontal in-mixing into the lower tropical stratosphere, J. Geophys. Res., 114, D19111, doi:10.1029/2009JD011955, 2009.

Konopka, P., Grooß, J.-U., Günther, G., Ploeger, F., Pommrich, R., Müller, R. and Livesey, N.: Annual cycle of ozone at and above the tropical tropopause: observations versus simulations with the Chemical Lagrangian Model of the Stratosphere (CLaMS), Atmos. Chem. Phys., 10, 121-132, doi:10.5194/acp-10-121-2010, 2010.

Liu, C., Zipser, E., Garrett, T., Jiang, J. H., and Su, H.: How do the water vapor and carbon monoxide "tape recorders" start near the tropical tropopause?, Geophys. Res. Lett., 34, L09804, doi:10.1029/2006GL029234, 2007.

Livesey, N. J., Filipiak, M. J., Froidevaux, L., Read, W. G., Lambert, A., Santee, M. L., Jiang, J. H., Pumphrey, H. C., Waters, J. W., Cofield, R. E., Cuddy, D. T., Daffer, W. H., Drouin, B. J., Fuller, R. A., Jarnot, R. F., Jiang, Y. B., Knosp, B. W., Li, Q. B., Perun, V. S., Schwartz, M. J., Snyder, W. V., Stek, P. C., Thurstans, R. P., Wagner, P. A., Avery, M., Browell, E. V., Cam- 
mas, J.-P., E. Christensen, L., Diskin, G. S., Gao, R.-S., Jost, H.-J., Loewenstein, M., Lopez, J. D., Nedelec, P., Osterman, G. B., Sachse, G. W., and Webster, C. R.: Validation of Aura Microwave Limb Sounder $\mathrm{O}_{3}$ and $\mathrm{CO}$ observations in the upper troposphere and lower stratosphere, J. Geophys. Res., 113, D15S02, doi:10.1029/2007JD008805, 2008.

Logan, J. A.: An analysis of ozonesonde data for the lower stratosphere: Recommendations for testing models, J. Geophys. Res., 104, 16151-16170, 1999.

Monge-Sanz B. M., Chipperfield M. P., Simmons A. J., Uppala S. M.: Mean age of air and transport in a CTM: Comparison of different ECMWF analyses, Geophys. Res. Lett., 34, L04801, doi:10.1029/2006GL028515, 2007.

Mote, P. W., Rosenlof, K. H., Mclntyre, M. E., Carr, E. S., Gille, J. C., Holton, J. R., Kinnersley, J. S., Pumphrey, H. C., Russell III, J. M., and Waters, J. W.: An atmospheric tape recorder: The imprint of tropical tropopause temperatures on stratospheric water vapor, J. Geophys. Res., 101, 3989-4006, 1996.

Niwano, M., Yamazaki, K., and Shiotani, M.: Seasonal and QBO variations in ascent rate in the tropical lower stratosphere as inferred from UARS HALOE trace gas data, J. Geophys. Res., 108, 4794, doi:10.1029/2003JD003871, 2003.

Ploeger, F., Konopka, P., Müller, R., Fueglistaler, S., Schmidt, T., Manners, J., Grooß, J.-U., Günther, G., de Forster, P. M., and Riese, M.: Horizontal transport affecting trace gas seasonality in the Tropical Tropopause Layer (TTL), J. Geophys. Res., 117, D09303, doi:10.1029/2011JD017267, 2012.

Randel, W. J., Garcia, R. R., and Wu, F.: Time-dependent upwelling in the tropical lower stratosphere estimated from the zonal-mean momentum budget, J. Atmos. Sci., 59, 2141-2152, 2002.

Randel, W. J., Park, M., Wu, F., and Livesey, N.: A large annual cycle in ozone above the tropical tropopause linked to the BrewerDobson circulation, J. Atmos. Sci., 64, 4479-4488, 2007.

Reed, R. J. and Vlcek, C. L.: The annual temperature variation in the lower tropical stratosphere, J. Atmos. Sci., 26, 163-167, 1969.

Rosenlof, K. H.: Seasonal cycle of the residual mean meridional circulation in the stratosphere, J. Geophys. Res., 100, 5173-5191, 1995.

Seviour, W. J. M., Butchart, N., and Hardiman, S. C.: The BrewerDobson circulation inferred from ERA-Interim, Q. J. Roy. Meteor. Soc., 138, 878-888, doi:10.1002/qj.966, 2011.
Schoeberl, M. R., Duncan, B. N., Douglass, A. R., Waters, J., Livesey, N., Read, W., and Filipiak, M.: The carbon monoxide tape recorder, Geophys. Res. Lett., 33, L12811, doi:10.1029/2006GL026178, 2006.

Schoeberl, M. R., Douglass, A. R., Newman, P. A., Lait, L. R., Lary, D., Waters, J., Livesey, N., Froidevaux, L., Lambert, A., Read, W., Filipiak, M. J., and Pumphrey, H. C.: QBO and annual cycle variations in tropical lower stratosphere trace gases from HALOE and Aura MLS observations, J. Geophys. Res., 113, D05301, doi:10.1029/2007JD008678, 2008a.

Schoeberl, M. R., Douglass, A. R., Stolarski, R. S., Pawson, S., Strahan, S. E., and Read, W.: Comparison of lower stratospheric tropical mean vertical velocities, J. Geophys. Res., 113, D24109, doi:10.1029/2008JD010221, 2008b.

Thuburn, J. and Craig, G. C.: Stratospheric influence on tropopause height: The radiative constraint, J. Atmos. Sci., 57, 17-28, 2000.

Waters, J. W., Froidevaux, L., Harwood, R. S., Jarnot, R. F., Pickett, H. M., Read, W. G., Siegel, P. H., Cofield, R. E., Filipiak, M. J., Flower, D. A., Holden, J. R., Lau, G. K., Livesey, N. J., Manney, G.L., Pumphrey, H.C., Santee, M. L., Wu, D. L., Cuddy, D. T., Lay, R. R., Loo, M. S., Perun, V. S., Schwartz, M. J., Stek, P. C., Thurstans, R. P., Boyles, M. A., Chandra, K. M., Chavez, M. C., Gun-Shing, C., Chudasama, B. V., Dodge, R., Fuller, R. A., Girard, M. A., Jiang, J. H., Yibo, J., Knosp, B. W., LaBelle, R. C., Lam, J. C., Lee, K. A., Miller, D., Oswald, J. E., Patel, N. C., Pukala, D. M., Quintero, O., Scaff, D. M., Van Snyder, W., Tope, M. C., Wagner, P. A., and Walch, M. J.: The Earth Observing System Microwave Limb Sounder (EOS MLS) on the Aura Satellite, IEEE Trans. Geosci. Remote Sens., 44, 1075-1092, 2006.

Yang, Q., Fu, Q., Austin, J., Gettelman, A., Li, F., and Vömel, H.: Observationally derived and general circulation model simulated tropical stratospheric upward mass fluxes, J. Geophys. Res., 113, D00B07, doi:10.1029/2008JD009945, 2008.

Yang, Q., Fu, Q., and Hu, Y.: Radiative impacts of clouds in the tropical tropopause layer, J. Geophys. Res., 115, D00H12, doi:10.1029/2009JD012393, 2010.

Yulaeva, E., Holton, J. R., and Wallace, J. M.: On the cause of the annual cycle in tropical lower-stratospheric temperature, J. Atmos. Sci., 51, 169-174, 1994. 